\title{
Effects of Modified Ground Structure on a CPW-fed Patch Antenna
}

\author{
Janmoni Borah ${ }^{1}$, Tasher Ali Sheikh ${ }^{2}$, and Sahadev Roy ${ }^{3}$ \\ National Institute of Technology, Arunachal Pradesh, India \\ borah1989@gmail.com ${ }^{1}$,tasher372@gmail.com ${ }^{2}$,sdr.ece@nitap.in ${ }^{3}$
}

\begin{abstract}
This paper presents a study of a coplanar waveguide (CPW-fed) antenna using a Modified Ground Structure (MGS). The antennas studied are relatively small in size (17x 20) $\mathrm{mm}^{2}$ and was designed on a low-cost FR-4 substrate. The presented antenna models shows improvements in the impedance bandwidth, the center frequency and operating bands with the stages of modification being introduced in the ground structure. The designed antennas were simulated using Ansoft HFSS, a FEM based simulator and antenna's characteristics such as Reflection coefficient, Center frequency, Operating frequency bands, Impedance bandwidth, and VSWR are reported in this paper.
\end{abstract}

Keywords: CPW-fed, FR-4 substrate, MGS, S11, Impedance bandwidth, VSWR

\section{Introduction}

With the increase in demand for wireless communication, an antenna designed with CPW structure has became more applicable in today's era of multi-band application. CPW structure allows etching of patch and ground of an antenna on the same side of a substrate thereby reduces the complexity and makes fabrication easier. Most of the CPW-fed monopole antennas were proposed because of attractive characteristics such as low cost, light weight, compact size and multiresonance modes. In [1-4], different techniques of designing dual-band WLAN antenna have been proposed. In [1], Ali et al. have presented a dual-band antenna for WLAN band applications. In [5], Deshmukh et al. have shown a technique for bandwidth enhancement of microstrip antennas using $\lambda / 4$ resonant slots. In [6], some methods for designing compact, low-profile and broadband microstrip antennas were discussed. The various feed structures such as the probe, the microstrip, and the coplanar waveguide (CPW) were shown in [7-16].

In this paper, a relatively small CPW-fed antenna of dimension $(17 \times 20) \mathrm{mm}^{2}$ has been studied with some stages of modification being introduced in the ground structures and was designed on a low-cost FR-4 substrate. The antenna models show good improvements related to frequency of operation, operating frequency bands and impedance bandwidth with the introduction of ground levels and resulted in a dual frequency operation. The antenna's performance was simulated using Ansoft HFSS.

\section{Basic Antenna Model}

The basic CPW-fed antenna model and its geometry are shown in Figure 1 and made to work as reference antenna for further study in this research. The parameters for the antenna shown in Figure 1 are tabulated in Table 1, and were optimized using Ansoft HFSS software. In this section, antenna characteristics such as reflection coefficient, center frequency, VSWR, operating frequency bands and impedance bandwidths are simulated for Figure 1 by varying the feed and step width with a constant length of 4 and $2.43 \mathrm{~mm}$ respectively, and obtained results are tabulated in Table 2. 


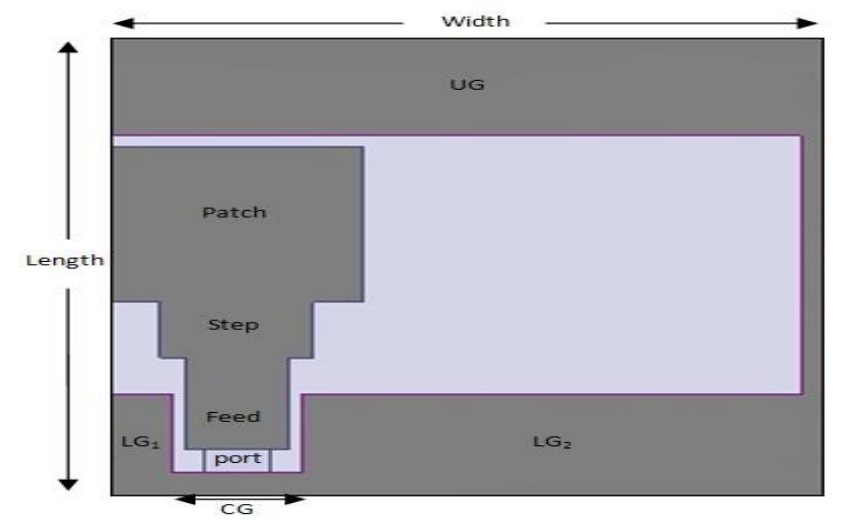

Figure 1. Geometry of the Basic Antenna Model

Table 1. Parameters for the Antennas Shown in Figure 1

\begin{tabular}{|c|c|c|c|c|c|}
\hline \multirow{2}{*}{\multicolumn{3}{|c|}{ Parameter }} & \multicolumn{3}{|c|}{$\operatorname{Size}(\mathrm{mm})$} \\
\hline & & & Width & Length & Height \\
\hline \multicolumn{3}{|c|}{ Substrate } & 17.00 & 20.00 & 1.00 \\
\hline \multicolumn{3}{|c|}{ Patch } & 6.00 & 6.78 & 0.02 \\
\hline \multicolumn{3}{|c|}{ Step } & 3.67 & 2.43 & 0.02 \\
\hline \multicolumn{3}{|c|}{ Feed } & 2.50 & 4.00 & 0.02 \\
\hline \multicolumn{3}{|c|}{ Port (rectangular sheet) } & 1.55 & 1.04 & 0.00 \\
\hline \multirow{4}{*}{ Grounds } & Upper ground & $\mathrm{UG}$ & 17.00 & 4.25 & 0.02 \\
\hline & \multirow[t]{2}{*}{ Lower ground } & $\mathrm{LG}_{1}$ & 1.45 & 4.40 & 0.02 \\
\hline & & $\mathrm{LG}_{2}$ & 12.45 & 4.40 & 0.02 \\
\hline & $\begin{array}{l}\text { Connecting } \\
\text { ground }\end{array}$ & $\mathrm{CG}$ & 3.10 & 0.96 & 0.02 \\
\hline
\end{tabular}

Table 2. Simulated Results for Figure 1

\begin{tabular}{|c|c|c|c|c|c|c|}
\hline $\begin{array}{c}\text { Step } \\
\text { Width } \\
(\mathrm{mm})\end{array}$ & $\begin{array}{c}\text { Feed } \\
\text { Width } \\
(\mathrm{mm})\end{array}$ & $\begin{array}{c}\text { S11 } \\
(\mathrm{dB})\end{array}$ & $\begin{array}{c}\text { Center } \\
\text { freq. } \\
(\mathrm{GHz})\end{array}$ & $\begin{array}{c}\text { Freq. } \\
\text { Band at } \\
-10 \mathrm{~dB} \\
(\mathrm{GHz})\end{array}$ & $\begin{array}{c}\text { Band- } \\
\text { width } \\
\text { at } \\
-10 \mathrm{~dB} \\
(\mathrm{GHz})\end{array}$ & VSWR \\
\hline 3.67 & 2.7 & -9.6707 & 1.002 & 0 & 0 & 1.9782 \\
\hline 3.67 & 2.5 & -9.0955 & 1.002 & 0 & 0 & 2.0813 \\
\hline 4.67 & 2.7 & -9.3760 & 1.002 & 0 & 0 & 2.0293 \\
\hline 6.00 & 2.7 & -9.5953 & 1.002 & 0 & 0 & 1.9909 \\
\hline
\end{tabular}

\section{Modification of Grounds}

This section presents the stages of modification being introduced in the ground layer of the antenna shown in Fig. 1 and the effects and consequences of using Modified Ground Structure (MGS) is also described. The study begins with a reference antenna (Antenna I) and finally to an Antenna IV. The reference antenna (Antenna I) is further studied here by introducing some MGSs with an optimum feed size $(2.5 \mathrm{x} 4 \mathrm{x} 0.02)$ and step size $(3.67 \mathrm{x}$ $2.43 \times 0.02$ ). The parameters considered for Antenna I-IV are tabulated in Table 3. 
Table 3. Parameters for the Antenna I-IV

\begin{tabular}{|c|c|c|c|c|c|}
\hline \multirow{2}{*}{\multicolumn{3}{|c|}{ Parameter }} & \multicolumn{3}{|c|}{$\operatorname{Size}(\mathrm{mm})$} \\
\hline & & & Width & $\begin{array}{l}\text { Lengt } \\
\mathrm{h}\end{array}$ & Height \\
\hline \multicolumn{3}{|c|}{ Substrate } & 17.00 & 20.00 & 1.00 \\
\hline \multirow{2}{*}{\multicolumn{3}{|c|}{ Patch }} & 6.00 & 6.78 & 0.02 \\
\hline \multirow{2}{*}{\multicolumn{3}{|c|}{$\begin{array}{l}\text { Step } \\
\text { Feed }\end{array}$}} & 3.67 & 2.43 & 0.02 \\
\hline & & & 2.50 & 4.00 & 0.02 \\
\hline \multicolumn{3}{|c|}{ Lumped Port (rectangular sheet) } & 1.55 & 1.04 & 0.00 \\
\hline \multirow{7}{*}{ Grounds } & $\begin{array}{l}\text { Upper } \\
\text { ground }\end{array}$ & UG & 17.00 & 4.25 & 0.02 \\
\hline & \multirow{5}{*}{$\begin{array}{l}\text { Lower } \\
\text { ground }\end{array}$} & $\mathrm{LG}_{1}$ & 1.45 & 4.40 & 0.02 \\
\hline & & $\mathrm{LG}_{2}$ & 12.45 & 4.40 & 0.02 \\
\hline & & $\mathrm{LG}_{3}$ & 8.375 & 3.60 & 0.02 \\
\hline & & $\mathrm{LG}_{4}$ & 2.625 & 1.60 & 0.02 \\
\hline & & $\mathrm{LG}_{5}$ & 1.3125 & 1.00 & 0.02 \\
\hline & $\begin{array}{l}\text { Connecting } \\
\text { ground }\end{array}$ & $\mathrm{CG}$ & 3.10 & 0.96 & 0.02 \\
\hline
\end{tabular}

The effects and consequences of modifying the ground of the antenna are explained in below:

\subsection{Effect of MGS ( $\mathbf{L G}_{1-2} \&$ UG)}

The geometry of Antenna I is shown in Fig. 2(a) and the obtained reflection coefficient plot is shown in the Fig. 2(b). It is seen that the Antenna I generates a resonant frequency of $1.002 \mathrm{GHz}$ with a reflection coefficient $\leq-5 \mathrm{~dB}(-9.0955 \mathrm{~dB})$.

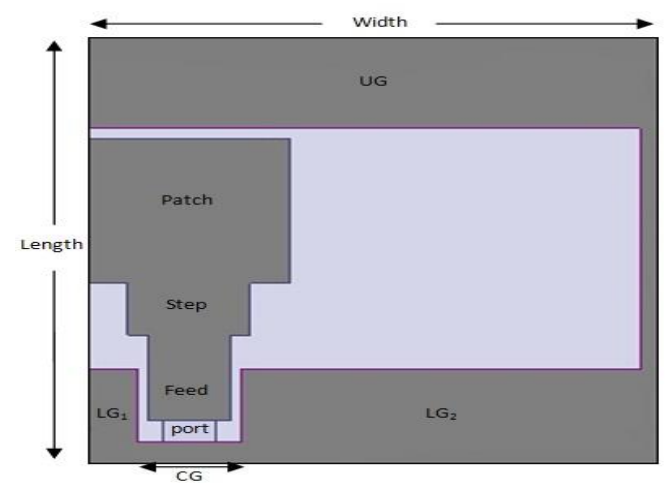

(a)

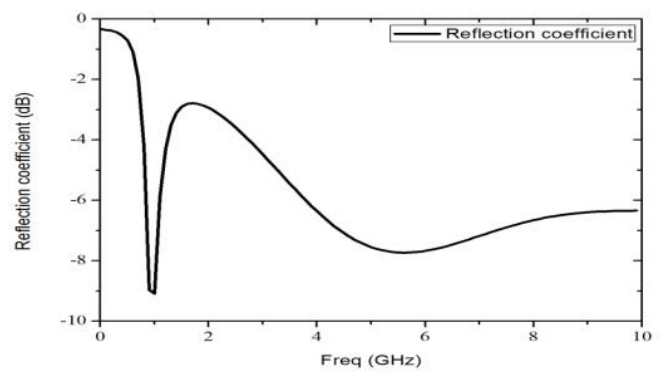

(b)

Figure 2. (a) Geometry of Antenna I, and (b) Simulated ReflectionCoefficient

\subsection{Effect of $\mathbf{L G}_{1-3} \& \mathbf{U G}$}

The Antenna II and its geometry are shown in Figure 3(a) and the obtained reflection coefficient plot is shown in the Figure 3(b). It is seen that by adding $\mathrm{LG}_{3}$ to Antenna I, resonant frequency increases from $1.002 \mathrm{GHz}$ to $1.102 \mathrm{GHz}$ resulting in a reflection coefficient $\leq-10 \mathrm{~dB}(-11.2018 \mathrm{~dB})$. 


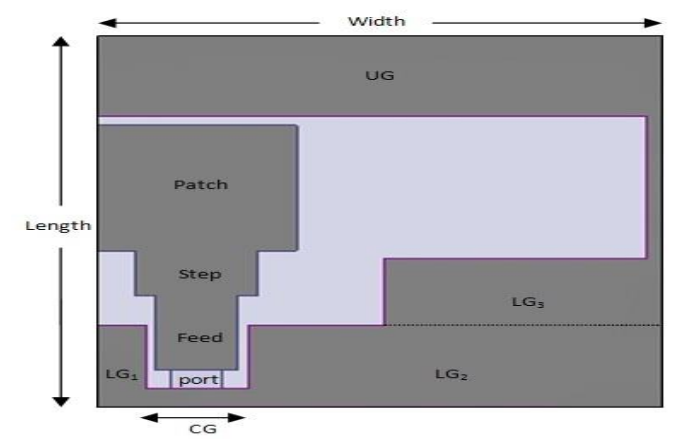

(a)

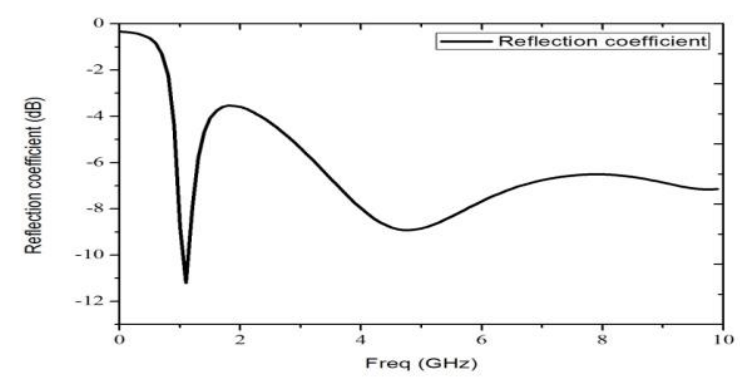

(b)

Figure 3. (a) Geometry of Antenna II, and (b) Simulated ReflectionCoefficients

\subsection{Effect of $\mathbf{L G}_{1-4} \& \mathrm{UG}$}

The Antenna III and its geometry are shown in Figure 4(a). By adding ground $\mathrm{LG}_{4}$ to Antenna II, the resulted Antenna III starts exciting with resonant frequencies $1.102 \mathrm{GHz}$ and $5.102 \mathrm{GHz}$ with reflection coefficients $\leq-10 \mathrm{~dB}$ i.e., $-11.1761 \mathrm{~dB}$ and $-10.8226 \mathrm{~dB}$ respectively.

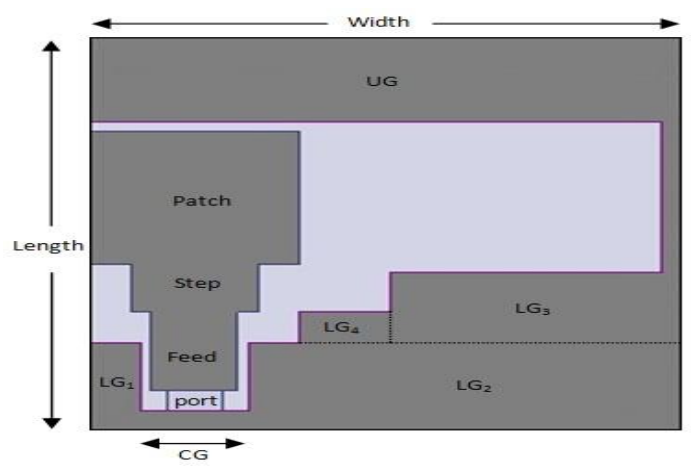

(a) 


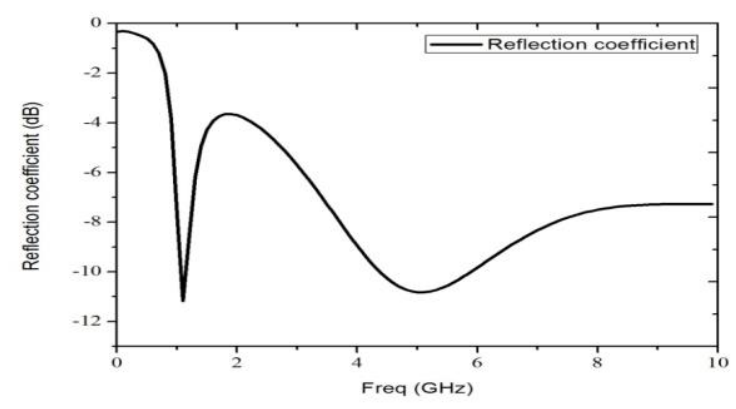

(b)

Figure 4. (a) Geometry of Antenna III, and (b) Simulated ReflectionCoefficients

\subsection{Effect of $\mathbf{L G}_{1-5} \& \mathrm{UG}$}

The geometry of Antenna IV is shown in Figure 5 (a) and the obtained simulated reflection coefficient is plotted in Figure 5(b). The obtained resonant frequencies are 1.102 and $5.002 \mathrm{GHz}$ with reflection coefficient of -10.9230 and $-11.2176 \mathrm{~dB}$ respectively.

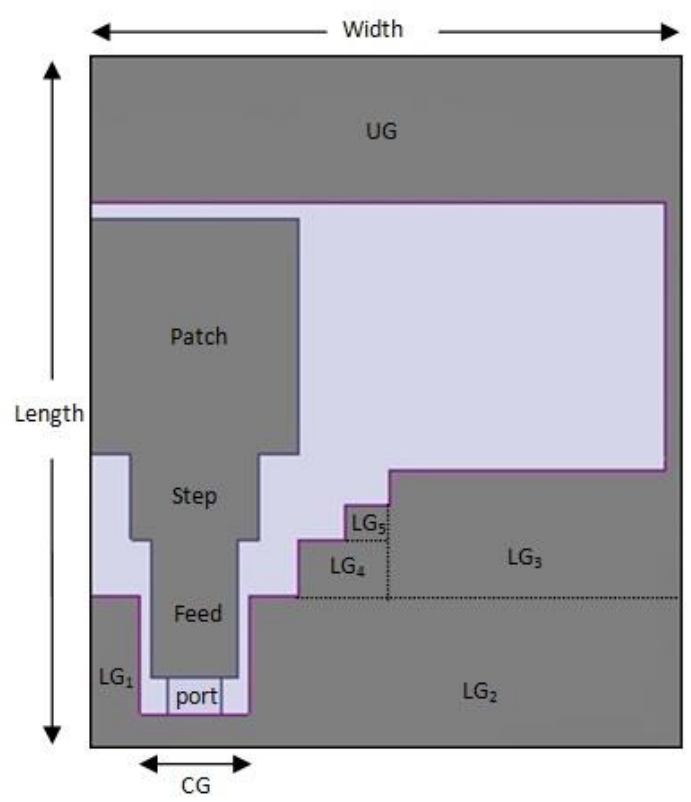

(a) 


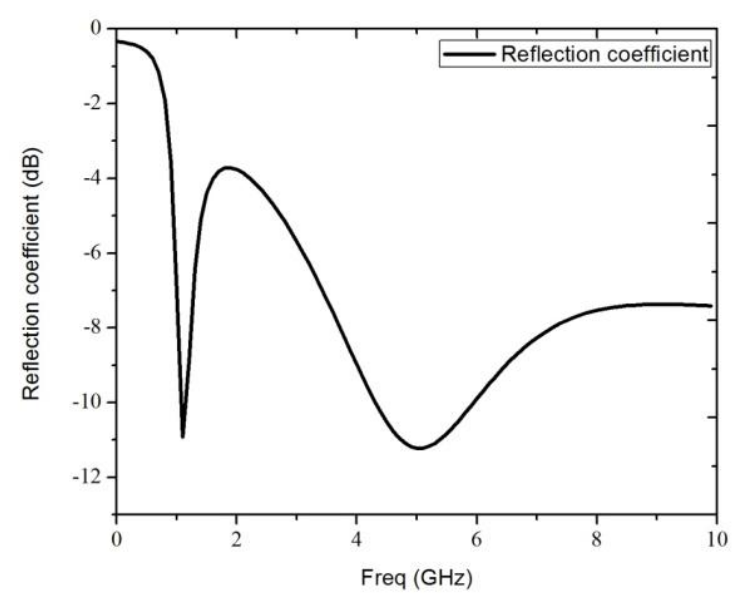

(b)

Figure 5. (a) Geometry of Antenna IV, and (b) Simulated ReflectionCoefficients

\section{Results and Analysis}

The CPW-fed antennas presented and studied in this paper have a dimension of $(17 \mathrm{x}$ 20) $\mathrm{mm}^{2}$ and was designed on a FR-4 substrate with dielectric constant 4.4 and thickness $1 \mathrm{~mm}$. The simulated results of the antennas plotted in Figure 2-5, such as Reflection coefficient (S11 in dB), VSWR, operating frequency bands, and center frequency and impedance bandwidth are tabulated in Table IV. The Figure 6 describes the comparative analysis of the antennas that was shown in Figure 2-5.

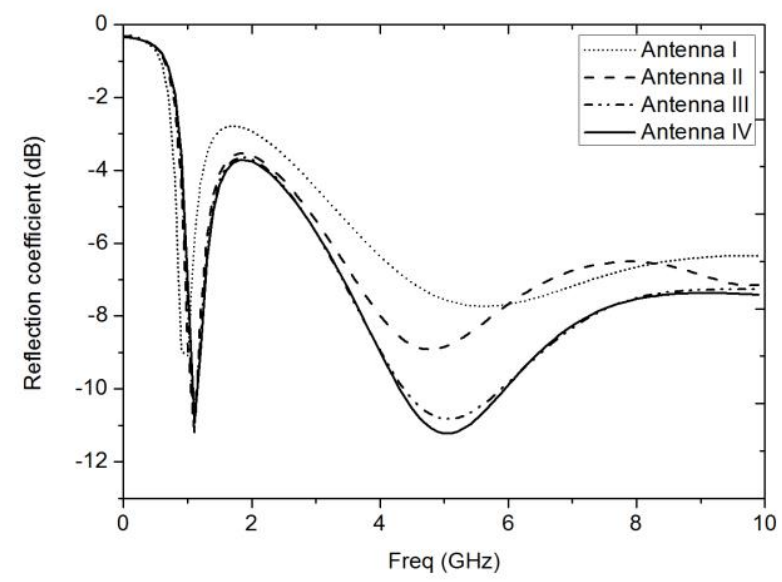

Figure 6. Simulated Reflection-Coefficients for Antenna I-IV 
Table 5. Simulated Results for the Antennas Shown in Figure 2-5.

\begin{tabular}{|c|c|c|c|c|c|}
\hline Antenna & $\begin{array}{c}\text { S11 } \\
(\mathrm{dB})\end{array}$ & $\begin{array}{c}\text { Center freq. } \\
(\mathrm{GHz})\end{array}$ & $\begin{array}{c}\text { Freq. Band at } \\
-10 \mathrm{~dB}(\mathrm{GHz})\end{array}$ & $\begin{array}{c}\text { Impedance } \\
\text { Bandwidth at } \\
10 \mathrm{~dB}(\mathrm{GHz})\end{array}$ & VSWR \\
\hline Antenna I & -9.0955 & 1.002 & 0 & 0 & 2.0813 \\
\hline Antenna II & -11.2018 & 1.102 & $1.10-1.13$ & 0.03 & 1.7600 \\
\hline Antenna III & -11.1761 & 1.102 & $1.06-1.14$ & 0.08 & 1.7631 \\
\cline { 2 - 7 } & -10.8226 & 5.102 & $4.37-5.89$ & 1.52 & 1.8076 \\
\hline Antenna IV & -10.9230 & 1.102 & $1.07-1.14$ & 0.07 & 1.7947 \\
& -11.2176 & 5.002 & $4.30-5.94$ & 1.64 & 1.7581 \\
\hline
\end{tabular}

From the tabulated results presented in Table IV, it is observed that, with the introduction and modification of grounds, the antenna performances such as operating frequency band, impedance bandwidth and center frequency shows good improvements and results in decrease of reflection coefficient to $\leq-10 \mathrm{~dB}$.

\section{Conclusion}

A small CPW-fed antenna is studied by introducing some modified ground structures. The antenna is realized with distinct operating bands and frequency. The overall CPW-fed technique thus enables the realization of a dual-band antenna maintaining the dimensions being considered in this research. The CPW-fed antenna has various advantages such as compactness, light weight, low cost, wide bandwidth and integrable with small device which makes an antenna well-suited for wireless applications.

\section{Acknowledgement}

First, we would like to thank IC Design and Fabrication centre, Jadavpur University (Kolkata), INDIA for providing software facilities to carry out this research work. We would also like to thank Electronics and Communication Engineering department of NIT Arunachal Pradesh, INDIA for valuable guidance and supports throughout this study.

\section{References}

[1] M. Ali, T. Sittironnarit, H. S. Hwang, R. A. Sadler, and G. J. Hayes, "Wide band/dual band packaged antenna for 5-6 GHz WLAN application," IEEE Trans. Antennas Propag., vol. 52, no. 2, (2004) February, pp. 610-615.

[2] L. Li, S.W. Cheung, and T. I. Yuk, "Dual band antenna with compact radiator for 2.4/5.2/5.8 GHz WLAN applications," IEEE Trans. Antennas Propag., vol. 60, no. 12, (2012) December, pp. 5924-5931.

[3] A. Khaleghi, "Dual band meander line antenna for wireless LAN communication," IEEE Trans. Antennas Propag., vol. 55, no. 3, (2007) March, pp. 1404-1409.

[4] C. Y. Huang and E. Z. Yu, "A slot-monopole antenna for dual-band WLAN applications," IEEE Antennas Wireless Propag. Lett., vol. 10, (2011), pp. 500-502.

[5] A. A. Deshmukh and K. P. Ray, "Compact broadband slotted rectangular microstrip antenna," IEEE Antennas Wireless Propag. Lett., vol. 8, (2009), pp. 1410-1413.

[6] K. L. Wong, Compact and Broadband Microstrip Antennas. New York, NY, USA: Wiley, (2002).

[7] Y. J. Han, "Fabrication and measurement of modified spiral-patch antenna for use as a triple-band (2.4 GHz/5 GHz) antenna," Microw. Opt.Technol. Lett., vol. 48, no. 7, (2006), pp. 1275-1279.

[8] J. Costantine, K. Y. Kabalan, A. El-Hajj, and M. Rammal, "New multiband microstrip antenna design for wireless communications," IEEE Trans. Antennas Propag. Mag., vol. 49, no. 6, (2007) December, pp. 181-186. 
[9] Panchatapa Bhattacharjee, Vivek Hanumante and Sahadev Roy "Design of U-Slot Rectangular Patch Antenna for Wireless LAN at 2.45GHz," 9th International Conference on Microwaves, Antenna, Propagation and Remote Sensing, ICMARS-2013, (2013) December, pp. 132-135.

[10] S. C. Kim, S. H. Lee, and Y. S. Kim, "Multi-band monopole antenna using meander structure for handheld terminals," Electron. Lett., vol. 44, no. 5, (2008), pp. 331-332.

[11] H. C. Go and Y.W. Jang, "Multi-band modified fork-shaped microstrip monopole antenna with ground plane including dual-triangle portion," Electron. Lett., vol. 40, no. 10, (2004), pp. 575-577.

[12] K. Seol, J. Jung, and J. Choi, "Multi-band monopole antenna with inverted U-shaped parasitic plane," Electron. Lett., vol. 42, no. 15, (2006), pp. 844-845.

[13] C. M. Wu, C. N. Chiu, and C. K. Hsu, "A new non uniform meandered and fork-type grounded antenna for triple-band WLAN applications," IEEE Antennas Wireless Propag. Lett., vol. 5, (2006), pp. 346-348.

[14] Y. Jee and Y. M. Seo, "Triple-band CPW-fed compact monopole antennas for GSM/PCS/DCS/WCDMA applications," Electron. Lett., vol. 45, no. 9, (2009), pp. 446-448.

[15] S. Chaimool and K. L. Chung, "CPW-fed mirrored-L monopole antenna with distinct triple bands for WiFi and WiMAX applications," Electron. Lett., vol. 45, no. 18, (2009), pp. 928-929.

[16] S. Xiaodi, "Small CPW-fed triple band microstrip monopole antenna for WLAN applications," Microw. Opt. Technol. Lett., vol. 51, no. 3, (2009), pp. 747-749.

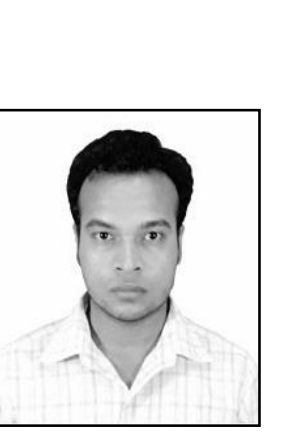

\begin{abstract}
Authors
Janmoni Borah, received his B.Tech degree in Electronics and Communication Engineering from Central Institute of Technology, Kokrajhar, India in 2013. He is currently pursuing M.Tech in Mobile Communication and Computing at National Institute of Technology, Arunachal Pradesh, India. His research interest includes Mobile communication, Microstrip antenna design for multi-band applications, Microstrip filter design and Green computing. He has published some research papers in International journals and conferences.
\end{abstract}

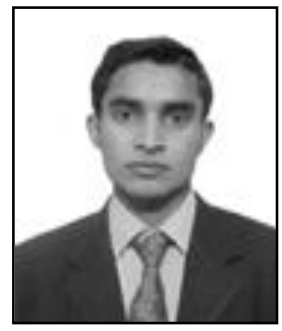

Tasher Ali Sheikh, received his B.Tech degree in Electronics and Communication Engineering from Central Institute of Technology (CIT), Kokrajhar, India in 2013. He has undertaken various microstrip filter based projects. His field of interest includes DSP, Microwave Filter and Antenna design and Mobile Communication. He enrolled for the Master of Technology in "Mobile Communication and Computing" at National Institute of Technology (NIT), Arunachal Pradesh, India in the month August, 2013. He has published some research paper in and international journals.

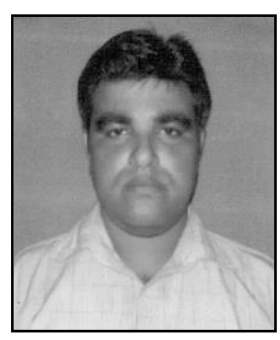

Sahadev Roy, Author's is currently working as an Assistant Professor in the Department of Electronics \& Communication Engineering at NIT, Arunachal Pradesh, India. He has more than 12 years' Experience in research and teaching field. He received his B.Sc. degree in Chemistry, B.Tech degree in ECE and M.Tech in Mechatronics from Bengal Engineering and Science University, Shibpur India. He is pursuing PhD in VLSI from NIT, Arunachal Pradesh. He has published more than 20 research articles in International referred journals. His research interest includes Robotics, Microwave and VLSI design. 